JOURNAL OF PUBLIC HEALTH FOR TROPICAL AND COASTAL REGION (JPHTCR)

Journal homepage: http:/ejournal2.undip.ac.id/index.php/jphtr/index

ISSN : 2597-438

\title{
Effectiveness Analysis of Single Dose Rifampicin-Post- Exposure Prophylaxis (SDR-PEP) as a Preventive Intervention for Leprosy Transmission: a Systematic Review of Randomized Controlled Trials
}

\author{
Muhammad Mikail Athif Zhafir Asyura1*, IIma Ranjani Wijaya1, Theetouch \\ Toshukowong $^{2}$, Wang Rui Sheng ${ }^{3}$ \\ ${ }^{1}$ Faculty of Medicine, University of Indonesia, Indonesia \\ ${ }^{2}$ Faculty of Medicine, Chiang Mai University, Thailand \\ ${ }^{3}$ Yong Loo Lin School of Medicine, National University of Singapore, Singapore \\ ${ }^{*}$ Corresponding Author. Email: muhammad.mikail91@ui.ac.id
}

\begin{abstract}
Introduction: Leprosy is a skin disease that reaches 200,000 cases annually. Considered a neglected tropical disease, $80 \%$ of annual leprosy remained in countries such as Brazil, India, and Indonesia. Multi-drug treatment is effective in curing leprosy but ineffective in preventing further transmission. The implementation of large-scale single dose rifampicin-post exposure prophylaxis suggests the inhibition of leprosy transmission and thus needs validation.

Methods: This systematic review was carried out based on the PRISMA statement from multiple databases using set keywords. A total of 646 studies were identified, followed by 4 randomized controlled trials included after screening.

Results: 86,502 subjects were divided into control and interventional groups and were to be followed-up in 2-6 years. Most studies showed a significant decrease of leprosy cases by 50$60 \%$. Furthermore, a complementary effect between single dose rifampicin-post exposure prophylaxis and Bacillus Calmette-Guérin vaccine was identified. Moreover, costeffectiveness of the intervention was analysed which resulted in IDR 80,414,775 being averted in its 25th year of implementation
\end{abstract}

Conclusion: The review established promising results of implementing single dose rifampicinpost exposure prophylaxis to prevent leprosy transmission. Further national scale intervention with a multi-layered approach is suggested to ensure full support and continuity of the largescale intervention

Keywords: chemoprophylaxis, leprosy, post exposure prophylaxis, single dose rifampicin

Article History: Received: $8^{\text {th }}$ April 2021, Revised: $22^{\text {th }}$ June 2021, Accepted: $9^{\text {th }}$ July 2021

\section{Introduction}

Leprosy, also known as Hansen's disease, is a skin disease caused by Mycobacterium leprae that has been plaguing the earth since 600 BC. Previously known as kushta, the disease has been associated with different religious texts, affirming the earliest aetiology of the disease being due to a curse or misfortune. 1,2 Only in 1873, the definitive cause of the disease was discovered by Dr. Genhard Armauer Hansen when he microscopically 
observed a multiple rod-shaped bacillus while examining a skin biopsy of a leprosy patient. $^{2}$ In the $21^{\text {st }}$ century, new cases of leprosy reached 200,000 new cases annually which is a significant decrease compared to the 12 million new cases in 1980. Despite the outstanding feat in intercepting transmission, the numbers have been stagnant for the past 8 years, signifying the still ongoing transmission of the disease. Currently, the disease is considered a neglected tropical disease (NTD) with countries such as Brazil, India, and Indonesia constituting $80 \%$ of the annual cases. Furthermore, the ongoing multidrug therapy (MDT) suggested by the World Health Organization (WHO) has been effective in alleviating symptoms of leprosy but not sufficient enough to prevent new cases of leprosy worldwide. This instance could be due to the decreasing resources being considered for leprosy worldwide and also antimicrobial and multidrug resistance that may rise due to the repeated and constant use of MDT on the bacteria. ${ }^{2,3}$

Moreover, this concern is exacerbated by the clustering of leprosy patients within endemic locations, translating to a high contact ratio between leprosy patients and the general public in a specific region, thus increasing the transmission rate of leprosy. ${ }^{2}$ In addition, due to the implicit nature of leprosy with long incubation periods, it remains a challenge to identify patients with leprosy without proper laboratory testing, increasing the general risk of the public that is unaware clinical signs of leprosy. Hence, there is an urgent need for an alternative or an additional intervention that does not only react to leprosy, but also act as a preventive measure against leprosy transmission. ${ }^{3}$

As a response, the implementation of large-scale immune-prophylaxis or chemoprophylaxis has been suggested but still not fully available, one of them being the administration of single dose rifampicin as a post-exposure prophylaxis (SDRPEP). By adopting a pre-emptive 'blanket' approach, the large-scale administration may aid in preventing leprosy transmission. Thus, this systematic review was made with the purpose of analysing the effectiveness of previous SDR-PEP randomized controlled trials and to validate its prospective feasibility as a preventive measure for leprosy treatment especially in Indonesia. By doing so, the group of authors hopes to contribute to the WHO formulated roadmap to combat the now 17 NTDs and to help in realising the sustainable development goals (SDG) number 3 , specifically target 3.3 which is to eradicate infectious and tropical diseases by $2030 .{ }^{3,4}$

\section{Methods}

\section{Search Strategy}

For this systematic review, literature search was carried out according to the Preferred Reporting Items for Systematic Review and Meta-Analysis (PRISMA). The following keywords were used to obtain relevant studies for this review; "Leprosy" AND ("Prophylaxis" OR "post exposure prophylaxis" OR "chemoprophylaxis") AND ("Single dose rifampicin" OR "Rifampicin") AND ("Prevention" OR "Feasibility"), utilising synonyms and implementing Medical Subject Headings (MeSH) where appropriate. Search strategy was conducted on 5 main databases namely: PubMed/MEDLINE, Science Direct, CENTRAL/Cochrane, Wiley Online Library, and Directory of Open Access Journals (DOAJ) for peer-reviewed studies published up to 12 March 2021.

\section{Inclusion \& Exclusion Criteria}

Throughout the synthesis of this paper, the inclusion criteria used were as follows: (1) study design being randomized controlled trials (RCT); (2) population endemic of leprosy or is in close contact with leprosy patients; (3) intervention in the form of SDR-PEP; (4) use of placebo or other intervention strategies for control; (5) outcome in the form of clinical manifestation of leprosy and incidence reduction where appropriate. While the exclusion criteria applied were: (1) Studies with irretrievable full text; (2) non-research articles such as reviews, advertorials, and conference abstracts; (3) Studies in languages other than Bahasa Indonesia, Thai, Chinese, and English. 
Data Extraction and Study Outcomes

Two independent reviewers conducted data extraction, with differences adjudicated by consensus from a separate third investigator. The information extracted from the included studies were: (1) author and year of publication; (2) study characteristics: location and design; (3) study population: sample size and subject characteristics; (4) interventions used; (5) follow-up period of study. Primary outcome from this study was the (1) clinical manifestation of leprosy with secondary outcomes being (2) incidence rate and (3) reduction in incidence.

\section{Risk of Bias Assessment}

Risk of bias (ROB) assessment was conducted using the Cochrane risk-of-bias tool for randomized controlled studies 2.0 to evaluate methodological quality. ${ }^{5}$ The ROB assessment tool has 5 main domains with each addressing the bias risk potentially arising from: randomization process, multiple deviations from the intended interventions, missing data, bias in outcome measurement, bias is result reporting. Response options were recorded in Yes, Probably Yes, Probably No, No, and Not Included which evaluates each domain to show low, some, or high risk of bias according to Agency for Healthcare Research and Quality (AHRQ). The assessment was performed separately by three independent investigators, with discrepancies being resolved by mutual agreement of all the investigators.

\section{Results}

Search Results

Search carried out on five international databases applying the set keywords resulted in 646 studies before screening. The 646 studies were then further evaluated via the examination of their title and abstract to ensure relevancy. After initial screening, 21 records were identified and 9 records after duplicates were excluded. Full-text screening was conducted on the 9 studies, resulting in 5 studies being excluded due to having irretrievable text and incompatible study design not relevant to this review. The full search strategy is shown as a PRISMA flowchart diagram in Figure 1.

\section{Characteristics of Included Studies}

Careful screening according to the inclusion and exclusion criteria resulted in 4 single centre RCTs conducted in Bangladesh with 3 of them being doubleblinded for their methodological process. In total, 86,502 subjects were tested which were close contacts of leprosy patients in endemic populations with effectiveness indicated by the number of clinical leprosy development after follow-up as the primary outcome. Two of the studies tested the effectiveness of SDR-PEP compared to a control group exclusively while the other two decided to test the effectiveness of SDR-PEP administration post Bacillus Calmette-Guérin (BCG) vaccination. Furthermore, all of the studies decided on 2 years as the most optimal follow-up period while 2 studies decided to continue follow-up up to 6 years despite the results not being particularly significant. The 4 RCTs were assessed using the Cochrane Risk-of-Bias tool 2.0 with 3 studies achieving good quality while one having fair quality due to not being able to conduct double blinding within its trial. The complete summary table of study characteristics and outcome is shown as Table 1. while the summarised ROB shown as Table 2. ${ }^{6-9}$ 


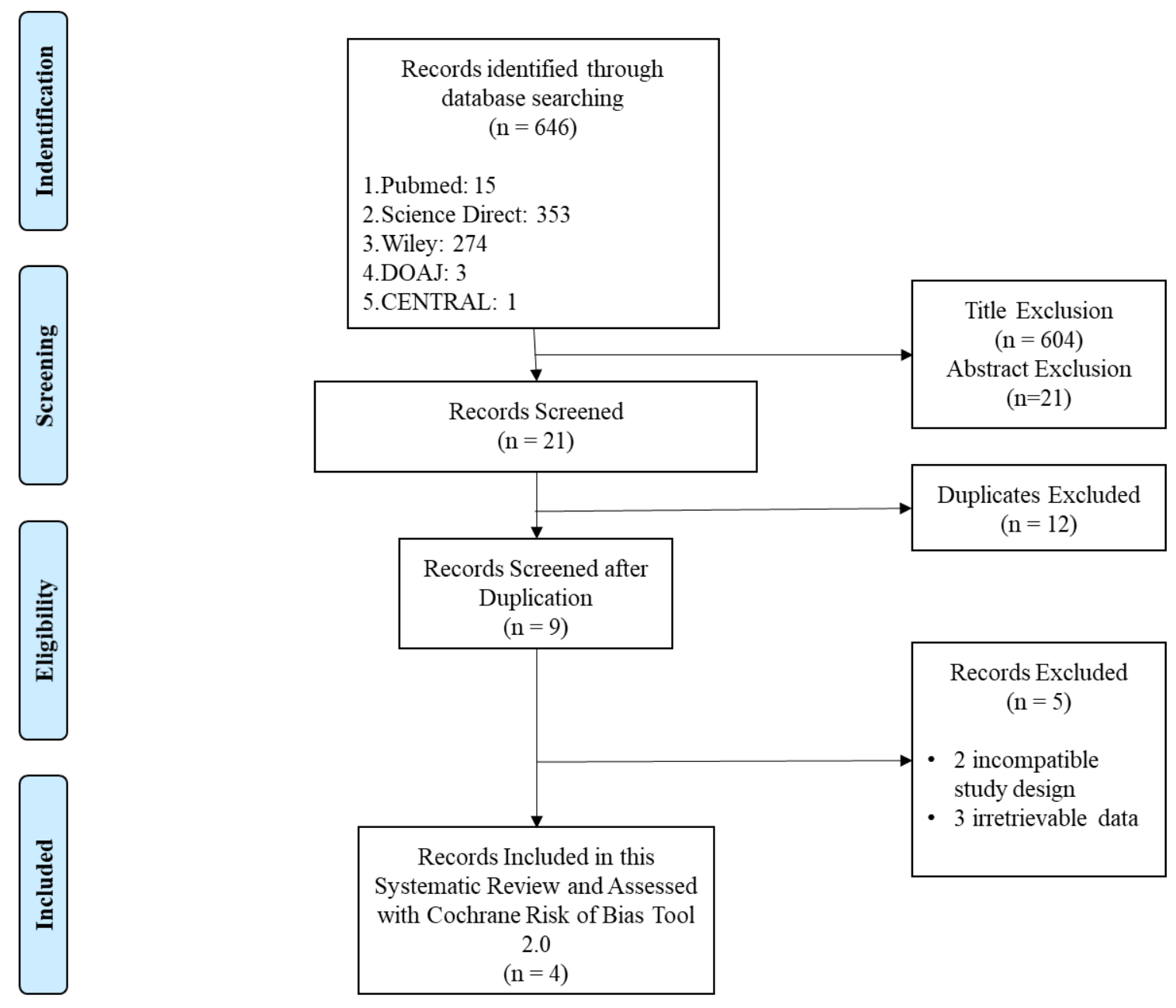

Figure 1. PRISMA Flow Chart Diagram of Search Strategies

\section{Discussion}

Current state of Multi Drug Therapy (MDT) on Leprosy

The combination of dapsone, clofazimine, and rifampicin or collectively called MDT has been coined the treatment of choice for leprosy by the WHO since the 1940 's. ${ }^{6}$ Combined, the administration of the drug according to the WHO protocol yielded an overall efficacy rate of $60 \%$ and has succeeded in pressing the global concern of the disease, placing it under the category of NTD. 5,10 Despite that, the treatment has gained much scepticism regarding its effectiveness by dermatologist from countries endemic for leprosy due to its long duration of treatment. ${ }^{10}$ Other than inducing drug resistance among Mycobacterium leprae, the effectiveness of the chemotherapy has remained stagnant shown by the unchanging trend and detection rate of leprosy over the past 70 years. ${ }^{8}$ On the other hand, novel treatments such as the administration of SDR-PEP has been shown to interrupt the transmission chain of M.leprae by $57 \%$ if given pre-emptively to close contact of leprosy patients, providing them innate protection against leprosy infection. $^{6-10}$ Hence, to anticipate the declining effectiveness of sole MDT as the golden standard treatment for leprosy, other potential alternatives taken from a different approach such as SDR-PEP are required to be explored extensively.

The potential of Single Dose Rifampicin Post Exposure Prophylaxis (SDR-PEP)

Leprosy as an infectious disease has been a hurdle for practitioners to intervene due to its elusive nature, long incubation period, and difficulty in clinical 
Table 1. Complete Summary of Study Characteristics and Outcome

\begin{tabular}{|c|c|c|c|c|c|c|c|c|c|c|}
\hline \multirow[b]{2}{*}{ Author; Year } & \multirow[b]{2}{*}{ Study Location } & \multirow[b]{2}{*}{ Study Design } & \multicolumn{2}{|c|}{ Study population } & \multirow[b]{2}{*}{ Intervention } & \multirow{2}{*}{$\begin{array}{l}\text { Follow-up } \\
\text { period } \\
\text { (years) }\end{array}$} & \multicolumn{4}{|c|}{ Study outcome } \\
\hline & & & $\begin{array}{c}\text { Sample } \\
\text { Size }\end{array}$ & $\begin{array}{l}\text { Characteristics of } \\
\text { study population }\end{array}$ & & & $\begin{array}{l}\text { Clinical leprosy } \\
\text { development }\end{array}$ & $\begin{array}{c}\text { Incidence rate } \\
(95 \% \mathrm{Cl})\end{array}$ & $\begin{array}{c}\text { Incidence } \\
\text { reduction }(95 \% \mathrm{Cl})\end{array}$ & $\mathrm{p}$ \\
\hline \multirow{4}{*}{ Moet; $2008^{6}$} & \multirow{4}{*}{$\begin{array}{l}\text { two districts of } \\
\text { northwest } \\
\text { Bangladesh }\end{array}$} & \multirow{4}{*}{$\begin{array}{l}\text { Single centre, } \\
\text { double blind, } \\
\text { cluster } \\
\text { randomised, } \\
\text { placebo- } \\
\text { controlled trial. }\end{array}$} & \multirow{4}{*}{21,711} & \multirow{4}{*}{$\begin{array}{c}\text { close contacts of } \\
1,037 \text { patients with } \\
\text { newly diagnosed } \\
\text { leprosy }\end{array}$} & \multirow{2}{*}{$\begin{array}{c}150 \mathrm{mg} \text { SDR-PEP } \\
\text { capsules }(n=10,857)\end{array}$} & $1-2$ & $67 / 9,939$ & $\begin{array}{c}33.59 \\
(26.42-42.72) \\
\end{array}$ & $\begin{array}{c}56.5 \\
(32.9-71.9) \\
\end{array}$ & $\begin{array}{c}0.000 \\
2\end{array}$ \\
\hline & & & & & & $3-4$ & $24 / 9,361$ & $\begin{array}{c}12.80 \\
(8.58-19.11)\end{array}$ & $\begin{array}{c}34.9 \\
(9.8-53.0) \\
\end{array}$ & 0.02 \\
\hline & & & & & \multirow{2}{*}{$\begin{array}{c}150 \mathrm{mg} \text { placebo } \\
\text { capsules }(\mathrm{n}=10,854)\end{array}$} & $1-2$ & 29/9,922 & $\begin{array}{c}14.59 \\
(10.14-21.01)\end{array}$ & $\mathrm{N} / \mathrm{A}$ & $\mathrm{N} / \mathrm{A}$ \\
\hline & & & & & & $3-4$ & $30 / 9,358$ & $\begin{array}{c}16.00 \\
(11.18-22.90) \\
\end{array}$ & $\mathrm{N} / \mathrm{A}$ & $\mathrm{N} / \mathrm{A}$ \\
\hline \multirow{4}{*}{$\begin{array}{l}\text { Richardus; } \\
\qquad 2019^{7}\end{array}$} & \multirow{4}{*}{$\begin{array}{l}\text { northwest } \\
\text { Bangladesh }\end{array}$} & \multirow{4}{*}{$\begin{array}{l}\text { single-centre, } \\
\text { cluster- } \\
\text { randomized } \\
\text { controlled trial }\end{array}$} & \multirow{4}{*}{14,988} & \multirow{4}{*}{$\begin{array}{c}\text { close contacts of } \\
1,552 \text { patients with } \\
\text { newly diagnosed } \\
\text { leprosy }\end{array}$} & \multirow{2}{*}{$\begin{array}{l}\text { BCG vaccination + } \\
150 \mathrm{mg} \text { SDR-PEP } \\
\text { capsules }(n=7,609)\end{array}$} & 1 & $19 / 7,228$ & $\begin{array}{c}44.0 \\
(30-64) \\
\end{array}$ & $42(13-70)$ & 0.148 \\
\hline & & & & & & 2 & $28 / 7,087$ & $\begin{array}{c}34.0 \\
(23-50)\end{array}$ & $\mathrm{N} / \mathrm{A}$ & $\mathrm{N} / \mathrm{A}$ \\
\hline & & & & & \multirow{2}{*}{$\begin{array}{l}\text { BCG vaccination } \\
\text { only }(n=7,379)\end{array}$} & 1 & $27 / 7,250$ & $31(20-48)$ & $\mathrm{N} / \mathrm{A}$ & $\mathrm{N} / \mathrm{A}$ \\
\hline & & & & & & 2 & $24 / 7,118$ & $42(28-59)$ & $\mathrm{N} / \mathrm{A}$ & $\mathrm{N} / \mathrm{A}$ \\
\hline \multirow{6}{*}{$\begin{array}{l}\text { Feenstra; } \\
2012^{8}\end{array}$} & \multirow{6}{*}{$\begin{array}{l}\text { Rangpur and } \\
\text { Nilphamari in } \\
\text { northwest } \\
\text { Bangladesh }\end{array}$} & \multirow{6}{*}{$\begin{array}{l}\text { single-centre, } \\
\text { double blinded, } \\
\text { cluster- } \\
\text { randomized, } \\
\text { placebo- } \\
\text { controlled trial }\end{array}$} & \multirow{6}{*}{28,092} & \multirow{6}{*}{$\begin{array}{c}\text { close contacts of } \\
1,037 \text { patients with } \\
\text { newly diagnosed } \\
\text { leprosy }\end{array}$} & \multirow{3}{*}{$\begin{array}{l}150 \mathrm{mg} \text { SDR-PEP } \\
\text { capsules }(\mathrm{n}=9,951)\end{array}$} & $1-2$ & 29/9,922 & $\begin{array}{c}14.6 \\
(10.1-21.0) \\
\end{array}$ & 39 & $\mathrm{~N} / \mathrm{A}$ \\
\hline & & & & & & $3-4$ & $30 / 9,358$ & $\begin{array}{c}16.0 \\
(11.2-22.9) \\
\end{array}$ & $\mathrm{N} / \mathrm{A}$ & $\mathrm{N} / \mathrm{A}$ \\
\hline & & & & & & $5-6$ & $18 / 8,741$ & $\begin{array}{c}10.3 \\
(6.5-16.3) \\
\end{array}$ & $\begin{array}{c}5.1 \\
(0.6-9.5) \\
\end{array}$ & 0.025 \\
\hline & & & & & \multirow{3}{*}{$\begin{array}{c}150 \mathrm{mg} \text { placebo } \\
\text { capsules }(\mathrm{n}=10,006)\end{array}$} & $1-2$ & $67 / 9,939$ & $\begin{array}{c}33.6 \\
(26.4-42.7)\end{array}$ & $\mathrm{N} / \mathrm{A}$ & $\mathrm{N} / \mathrm{A}$ \\
\hline & & & & & & $3-4$ & $24 / 9,361$ & $\begin{array}{c}12.8 \\
(8.6-19.1)\end{array}$ & $\mathrm{N} / \mathrm{A}$ & $\mathrm{N} / \mathrm{A}$ \\
\hline & & & & & & $5-6$ & $17 / 8,873$ & $9.6(5.9-15.4)$ & $\mathrm{N} / \mathrm{A}$ & $\mathrm{N} / \mathrm{A}$ \\
\hline \multirow{4}{*}{$\begin{array}{l}\text { Schuring; } \\
2009^{9}\end{array}$} & \multirow{4}{*}{$\begin{array}{l}\text { Rangpur and } \\
\text { Nilphamari in } \\
\text { northwest } \\
\text { Bangladesh }\end{array}$} & \multirow{4}{*}{$\begin{array}{l}\text { Single centre, } \\
\text { double blind, } \\
\text { cluster } \\
\text { randomised, } \\
\text { placebo- } \\
\text { controlled trial. }\end{array}$} & \multirow{4}{*}{21,711} & \multirow{4}{*}{$\begin{array}{c}\text { close contacts of } \\
1,037 \text { patients with } \\
\text { newly diagnosed } \\
\text { leprosy }\end{array}$} & None $(n=6,470)$ & \multirow{4}{*}{$1-2$} & $52 / 6,470$ & N/A & $\mathrm{N} / \mathrm{A}$ & $\mathrm{N} / \mathrm{A}$ \\
\hline & & & & & $\begin{array}{l}\text { BCG Vaccination } \\
\text { only }(n=4,306)\end{array}$ & & $15 / 4,306$ & $\mathrm{~N} / \mathrm{A}$ & 57 (24-75) & $<0.05$ \\
\hline & & & & & $\begin{array}{c}150 \text { mg SDR-PEP } \\
\text { capsules only } \\
(n=6,484)\end{array}$ & & $22 / 6,484$ & $\mathrm{~N} / \mathrm{A}$ & $58(30-74)$ & $<0.05$ \\
\hline & & & & & $\begin{array}{l}\text { BCG vaccination + } \\
150 \mathrm{mg} \text { SDR-PEP } \\
\text { capsules }(\mathrm{n}=4,266)\end{array}$ & & $7 / 4,266$ & $\mathrm{~N} / \mathrm{A}$ & $80(50-92)$ & $<0.05$ \\
\hline
\end{tabular}

Legend: SDR: Single Dose Rifampicin; BGC: Bacillus Calmette-Guérin; Cl: Confidence Interval 
Table 2. Summary of Bias Assessment using RoB 2

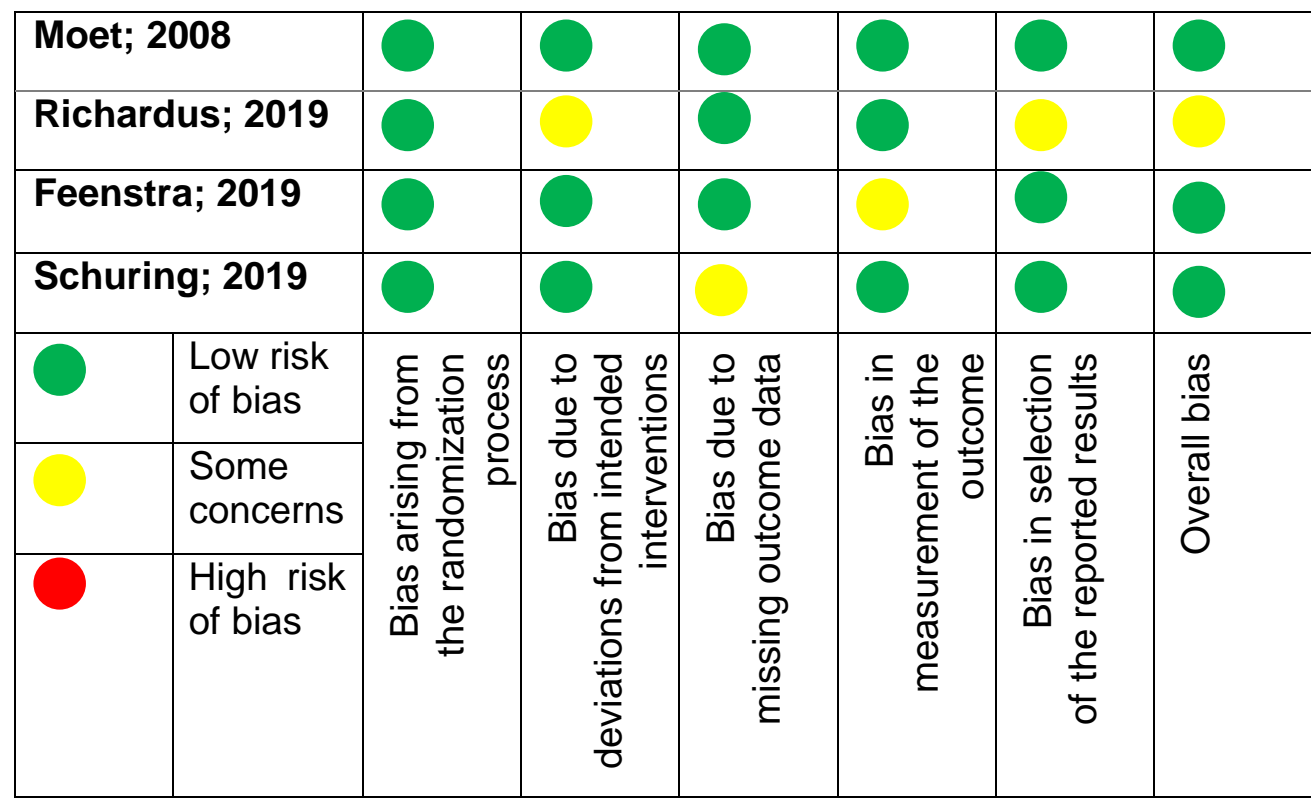

diagnosis. Being a skin disease, leprosy is commonly associated with a defined skin lesion with loss of sensation, visible surface deformities on the skin, and the loss of sensation or malaise of the extremities due to the thickening of the patient's nerve. Although, those symptoms only manifest after 5 years of incubation in which the patient will be asymptomatic but tested positive by polymerase chain reaction (PCR) for the bacteria and is able to transmit the bacteria towards their close contacts. ${ }^{11}$ Rifampicin or rifampin (3-(4methyl-1-piperazinyl)-imino-methyl

rifamycin) is a drug that targets the deoxyribonuclease acid (DNA) replication process of the bacteria. Also considered under post-exposure prophylaxis (PEP) due to its property as an anti-Human immunodeficiency virus (anti-HIV) treatment, the drug specifically targets the $\beta$-subunit of the DNA-dependent ribonuclease acid (RNA) polymerase, preventing the subunit from binding with the bacteria's DNA and inhibiting mRNA transcription. With crucial genes not being transcribed, this leads to the inhibition of essential proteins for the bacteria to be translated, and thus initiating cell death. ${ }^{12}$ By utilising a 'blanket group' approach, in which cost-effective treatments are administered in a large scale over an endemic area, more people, infected-or- not, are given a baseline protection that may protect them from the manifestation of leprosy especially during its premanifestation period. ${ }^{7-12}$

Effectiveness analysis of Single Dose Rifampicin - Post Exposure Prophylaxis (SDR-PEP)

From the 5 included studies, effectiveness of the treatment is predominantly determined by comparing the number of subjects that developed leprosy between the SDR-PEP group and the control group. Leprosy diagnosis was mostly confirmed by a medical or leprosy control officer that has at least 5 years of experience in diagnosing patients with leprosy. Generally, the SDR-PEP group in all the controlled studies showed fewer manifestation of clinically identified leprosy after follow up. 6-9 Studies conducted by Moet et al and Feenstra et al showed that the incidence rate of the SDR-PEP group to be half of the control group, with incidence reduction achieving 56.5\% [32.9,71.9] $(\mathrm{p}=0.0002)$ and $39 \%$ respectively. 6,8 Moreover, the same two studies also implemented follow-up periods of more than 2 years in which incidence reduction between the SDR-PEP and control group became less obvious and insignificant. ${ }^{6,8}$ However, despite the small incidence reduction of only $5.1 \%[0.6,9.5]$, Feenstra 
et al reported the findings to be statistically significant $(p=0.025)$, indicating the SDRPEP group is still better in preventing leprosy development. ${ }^{8}$ This finding provides valuable insight in determining the effective frequency of population wide SDR-PEP administration in ensuring maximal suppression of leprosy transmission. Furthermore, the administration of SDR-PEP as chemoprophylaxis following BCG immunization as an immune-prophylaxis according to Schuring et al proved impressive results with an incidence reduction of $80 \%[50,92](p<0.05)$, followed by Richardus et al's study with $42 \%[13,70]$ $(p=0.148) .{ }^{9}$ This finding is further supported by complementary reactional-effect suggested by the meta-analysis written by Schoenmakers et al. on the additive property of immune-prophylaxis and chemoprophylaxis in leprosy. ${ }^{13}$

\section{Applicability and cost effectiveness in Indonesian context}

All four of the included studies were conducted in Bangladesh. Demographically, the regions endemic for leprosy in Bangladesh and Indonesia would show similar characteristics as they belong in a lower to middle income family. 5,7 Furthermore, another study conducted by Tiwari et al. evaluated the costeffectiveness aspect of the SDR-PEP treatment in accordance with the Indian health system. From that study, it was estimated that each administration of SDRPEP would avert US\$ 2.9 or about IDR 41,107 and prospectively avert US $\$ 5,673$ or IDR $80,414,775$ in the 25 th year since its initial implementation. ${ }^{14,15}$ Bringing this into perspective, SDR-PEP or chemoprophylaxis in general has been pioneered by certain non-governmental organisations (NGO) that values the same goal of eradication leprosy and partnered with the Global Partnership for Zero Leprosy coalition. An example includes the Netherland Leprosy Relief (NLR) which is an NGO which has been introducing chemoprophylaxis in five different regions of Indonesia. Furthermore, similar NGOs have also developed leprosy-friendly village models where primary healthcare personnel are more sensitised to early signs of leprosy symptoms, hence enabling them to identify potential leprosy carriers and administer SDR-PEP sooner. ${ }^{16}$ Currently in Indonesia, treatment for leprosy patients still includes Multi Drug Treatment of Leprosy (MDTL) which are divided into two regimens: paucibacillary (PB) leprosy type and Multibacillary (MB) leprosy type. Although, research on SDRPEP implementation have been carried out with prospective results 5 years from now. Hence, SDR-PEP is a cost-effective strategy in the short and long term and is highly applicable in Indonesia based on the sample familiarity and current additional preventive effort being carried out in the country. ${ }^{17}$

\section{Study strength and limitations}

The strength of this review lies in the uniformity of the study design across the four studies; with all being large randomised controlled trials and $3 / 4$ being double-blinded. This homogeneity made the studies easily comparable and thus helped in forming links between them and synthesising justified conclusions. Furthermore, RCTs are commonly referred to as the golden standard for evidencebased medicine which is further strengthened by the elimination of selection, observational, and participant bias from double blinding. Moreover, the long period of follow-ups allows the definitive analysis of outcome in the short and long term. However, this systematic review is limited by the lack of variability in study locations and different control groups of each study. This difference may affect the comparison between the reduction in incidence values, making those comparisons not representative. Nevertheless, this can be compensated by firstly comparing and analysing studies with similar control groups in a meta-analysis.

\section{Conclusion}

In conclusion, leprosy has remained a prevalent problem in certain corners of the world, one of them being in Indonesia. The nationwide implementation of MDTs has been a huge success in curing and cutting the numbers of leprosy cases, but remained insufficient in inhibiting the steady transmission of the disease. The 
introduction of SDR-PEP as a cost-efficient and effective preventive method against leprosy transmission has shown promising results with $50-60 \%$ incidence reduction among endemic leprosy populations. By using a 'blanket' approach towards segmented regions that are considered leprosy clusters, transmission can be prevented prematurely and hence lowering the annual cases of leprosy. However, considering the limitations of this review, the author recommends more studies to be conducted in different countries endemic to leprosy and a review on biosafety of SDRPEP towards various populations.

In the implementation of the treatment, we recommend a multi-layered approach with multiple stakeholders to be involved in the dissemination of SDR-PEP. This approach is conducted by considering several suggestions which includes: Firstly, commitment of the local governance is necessary to ensure continuous support of the intervention. Secondly, structured planning, monitoring, and evaluation needs to be agreed upon before the execution. Thirdly, if possible, integrate SDR-PEP into pre-existing leprosy prevention systems especially regarding contact tracing and surveillance. Lastly, to coordinate the execution with established health institutions to certify proper publication and prospective analysis of the intervention. These recommendations are essential in establishing an effective public health approach against leprosy in Indonesia and thus achieving SDGs in terms of eradicating the epidemics of infectious and tropical diseases.

\section{Funding}

None were received

\section{Author Contribution}

According to the Contributor Roles Taxonomy (CRediT) author statement: MMAZA was responsible for Conceptualization, Methodology, Writing Original Draft, Visualization, Project administration. IRW was responsible for Writing-Original Draft, Investigation, Visualization. TT was responsible for: Writing - Original Draft, Investigation and
Resources. WRS was responsible for: Writing - Review \& Editing.

\section{Ethics approval}

Not applicable

\section{References}

1. Blok DJ, Vlas SJD, Richardus JH. Global elimination of leprosy by 2020: are we on track? Parasites and Vectors. 2015;8:548.

2. Bennet BH, Parker DL, Robson M. Leprosy: steps along the journey of eradication. Public Health Rep. 2008;123(2):198-205.

3. World Health Organization. Integrating neglected tropical diseases into global health and development: fourth WHO report on neglected tropical diseases. Geneva: World Health Organization; 2013.

4. United Nations. The 17 goals. New York: United Nations; 2020. Available from: https://sdgs.un.org/goals.

Accessed 9 Dec 2020

5. Cochrane. RoB 2: A revised Cochrane risk-of-bias tool for randomized trials. London: Cochrane; date unknown. Available from:

https://methods.cochrane.org/bias/ resources/rob-2-revised-cochranerisk-bias-tool-randomized-trials

6. Moet FJ, Pahan D, Oskam L, Richardus JH; COLEP Study Group. Effectiveness of single dose rifampicin in preventing leprosy in close contacts of patients with newly diagnosed leprosy: cluster randomised controlled trial. BMJ. 2008;336(7647):761-4.

7. Richardus R, Alam K, Kundu K, Chandra Roy J, Zafar T, Chowdhury AS, Nieboer D, Faber R, Butlin CR, Geluk A, Richardus J, et al. Effectiveness of single-dose rifampicin after BCG vaccination to prevent leprosy in close contacts of patients with newly diagnosed leprosy: A cluster randomized controlled trial. Int $\mathrm{J}$ Infect Dis. 2019;88:65-72. 
8. Feenstra SG, Pahan D, Moet FJ, Oskam L, Richardus JH. Patientrelated factors predicting the effectiveness of rifampicin chemoprophylaxis in contacts: 6 year follow up of the COLEP cohort in Bangladesh. Lepr Rev. 2012; 83(3): 292-304.

9. Schuring RP, Richardus $\mathrm{JH}$, Pahan $D$, Oskam L. Protective effect of the combination BCG vaccination and rifampicin prophylaxis in leprosy prevention. Vaccine. 2009;27(50): 7125-8. Available from: https://pubmed.ncbi.nlm.nih.gov/19 786134/

10. Malathi M, Thappa DM. Fixedduration therapy in leprosy: limitations and opportunities. Indian J Dermatol. 2013;58(2):93-100.

11. Mieras LF, Taal AT, van Brakel WH, Cambau E, Saunderson PR, Smith WCS, et al. An enhanced regimen as post-exposure chemoprophylaxis for leprosy: PEP+. BMC Infect Dis. 2018;18(1):506.

12. Cambau E, Williams DL. AntiLeprosy Drugs: Modes of Action and Mechanisms of Resistance in Mycobacterium leprae. International USA: Textbook of Leprosy. Available from: https://internationaltextbookoflepro sy.org/chapter/anti-leprosy-drugsmodes-action-and-mechanismsresistance-mycobacterium-leprae. Accessed 15 Dec 2020

13. Schoenmakers A, Mieras L, Budiawan T, van Brakel WH. The State of Affairs in Post-Exposure Leprosy Prevention: A Descriptive Meta-Analysis on Immuno- and Chemo-Prophylaxis. Res Rep Trop Med. 2020;11:97-117. doi: 10.2147/RRTM.S190300.

14. Tiwari A, Blok DJ, Arif M, Richardus $\mathrm{JH}$. Leprosy post-exposure prophylaxis in the Indian health system: A cost-effectiveness analysis. PLoS Negl Trop Dis. 2020;14(8):e0008521.

15. Schoenmakers, Anne; Mieras, Liesbeth; Budiawan, Teky; van Brakel, Wim H. Research and reports in tropical medicine. Macclesfield. 2020; 97-117.

16. Netherland Leprosy Relief. NLR Indonesia. Amsterdam: NLR. Available from: https://nlrinternational.org/what-wedo/indonesia/. Accessed 22 June 2021

17. Amelia N. Indonesia still ranked third with leprosy, UNAIR expert: We are all responsible for leprosy elimination. Surabaya: Universitas Airlangga. Available from: http://news.unair.ac.id/en/2020/01/ 29/indonesia-still-ranked-third-withleprosy-unair-expert-we-are-allresponsible-for-leprosy-elimination. Accessed 22 June 2021 